\title{
Arsenic and cadmium concentrations in legumes and cereals grown in the North Central Province, Sri Lanka and assessment of their health risk
}

\author{
E. M. R. K. B. Edirisinghe ${ }^{1 *}$ (D) and B. K. K. K. Jinadasa ${ }^{2}$
}

\begin{abstract}
Background: A total of 181 samples of cereals and legumes, including mustard, maize, finger millet, sesame, cowpea/black-eyed pea, Urad dal /split bean, foxtail millet, long bean and green gram from the North Central Province of Sri Lanka were analysed for arsenic (As) and cadmium (Cd) levels using atomic absorption spectrophotometry (AAS).

Findings: The As and Cd level in each sample was not significantly different. The mean level was found to be $48.90 \pm 34.63 \mu \mathrm{g} / \mathrm{kg}$ for As and $19.39 \pm 9.508 \mu \mathrm{g} / \mathrm{kg}$ for Cd on weight basis.

Conclusion: None of the foodstuffs studied contained $\mathrm{As}$ and $\mathrm{Cd}$ in levels exceeding the maximum permissible levels currently in force. Human health risk assessment of As and $\mathrm{Cd}$ in the foodstuffs was conducted and computed values indicated that there is no health risk due to consumption of the varieties studied. Nevertheless, the values, especially Total Hazard Quotient (THQ) emphasize the requirement of a comprehensive total diet study.
\end{abstract}

Keywords: Cereals, Legumes, Cadmium, Arsenic, Non-carcinogenic health risk, Carcinogenic effects, Dietary exposure, THQ

\section{Introduction}

The Agency for Toxic Substances and Disease Registry (ATSDR), 2017 ranked arsenic (As) and cadmium (Cd) at number one and seven, respectively, in the hazardous substances list (ATSDR, 2017). Most As and Cd exposure of humans happens directly or indirectly by ingestion - through drinking water or contaminated food. As and $\mathrm{Cd}$ contaminated plant crops are mostly those that grow in contaminated soil (Zhao et al., 2010). After accumulation of these non-essential trace elements (NETEs) into the crops, transfer occurs via the food chain and finally reaches the apex consumer in the food chain such as humans. In the mid 1950s in Japan, the "Itai-Itai disease" was recorded after consumption of $\mathrm{Cd}$ contaminated soybean and rice (Huang et al., 2009).

\footnotetext{
* Correspondence: ranjith_e@hotmail.com

${ }^{1}$ Department of Physical Sciences, Faculty of Applied Sciences, Rajarata

University of Sri Lanka, Mihintale, Sri Lanka

Full list of author information is available at the end of the article
}

Consumption of $\mathrm{Cd}$ resulted in stomach irritation, vomiting and diarrhea, while long-term exposure caused kidney disease, cancer and fragility at birth. Arsenic exposure may cause skin lesions, neuropathy, gastrointestinal diseases, cardiovascular diseases, cancer, and other ailments (Corguinha et al., 2015).

Air, water, and soil contamination are the sources of NETEs in agricultural areas. Agricultural land inputs such as fertilizers and pesticides are responsible for high NETE contamination of soil (Gunatilake et al., 2014). The NETEs in soil are transferred through the agricultural crops as they are deposited in the edible parts. The transfer rate depends on many different factors such as climatic, plant species, and genotypes (Corguinha et al., 2015).

North Central Province is the largest province in Sri Lanka, and the majority of the people (65\%) belong to the agricultural sector. Rice, the main crop of this area is cultivated by using the highly sophisticated ancient irrigation system from the Mahaweli River (Gunatilake et al., 2014). 
Apart from rice, other cereals, fruits, and vegetables are grown using seasonal tank water, rainwater and deep well water. The region is also associated with livestock farming.

Chronic renal failure (CRF) or chronic kidney disease $(\mathrm{CKDu})$ of unknown etiology is the biggest problem among the farmers in North Central Province (Bandara et al., 2010). Scientific research has found a number of causes for CKDu, of which one was As and Cd contamination (Bandarage, 2013). Jayasumana et al. (2015) reported considerable amount $(20.6-540.4 \mu \mathrm{g} / \mathrm{Kg})$ of arsenic in rice, which is depend on the fertilizers and pesticides used during the cultivation.

Exposure of humans to contaminated food is a general health concern in Sri Lanka. In view of this, the study assessed the As and Cd levels in the edible part of nine foodstuffs including legumes and cereals grown in the North Central Province of Sri Lanka. To the best of our knowledge, this is the first paper dealing with NETEs in cereals in this area, which is relevant not only to food security but also to commercial and economic aspects.

\section{Methods}

\section{Sample collection}

A total of 181 samples of nine crop species were randomly collected from farmers from the North Central Province of Sri Lanka during two growing cycles of the year 2016. The basic information such as sampling location, common name, variety etc. was collected at same time. The samples were prepared as per general procedures followed by consumers. The inedible parts were first removed, the edible portion was then washed thrice in distilled water, dried at room temperature, packed in polythene bags, sealed and transported to the laboratory for further analysis. While people in the area use groundwater or tap water to prepare the cereals in the kitchen, in the study we used distilled water to avoid any contamination from water. The type and number of samples were as follow; mustard (10), maize (45), finger millet (50), sesame (26), cowpea/blackeyed pea (17), Urad dal/ split bean (11), foxtail millet/ Thanahal (7), long bean/Mea (5) and green gram (10).

\section{Sample preparation and analysis}

Samples were ground using a domestic food blender and sieved. Then $0.5 \mathrm{~g}$ of each sample was mineralized in Teflon digestion vessels in a closed microwave accelerated system (CEM, MARS 6, USA) using nitric acid (Sigma, USA) as a reagent. Analysis of As and Cd was carried out by atomic absorption spectrophotometry, AAS (Varian 240 FS, Victoria, Australia) assisted by graphite tube atomizer (GTA 120). The calibration curve range $(\mu \mathrm{g} / \mathrm{L})$, wavelength $(\mathrm{nm})$, slit width $(\mathrm{nm})$ and lamp current $(\mathrm{mA})$ were as follow; for $\mathrm{Cd}, 0.5-3.0,228.8,0.5$, 4 and for As, 5.0-50.0, 193.7, 0.5, 10 respectively.
In order to check the purity of chemicals and glassware, blank samples were run with each batch. Analytical quality control was achieved by using the Certified Reference Materials (CRM) IRMM 804 (rice flour) from the Institute for Reference Materials and Measurement (IRMM), Belgium. All reagent blanks, samples, and CRM were run in duplicate. Validation of the analytical method was performed using limit of detection, LOD (3 x standard deviation, SD) and limit of quantification, LOQ (10 SD), correlation coefficient of calibration curve ( 0.999 or better), relative standard deviation, RSD between duplicates (10\% or below) and recovery of CRM (80-120\%).

The data were analysed using Microsoft Excel (MS office, 2010) and SPSS (Version 17) software. The mean, median, minimum-maximum value and standard deviation were calculated for $\mathrm{As}$ and $\mathrm{Cd}$ in each cereal/ legume type. The mean comparison ANOVA test was applied to find the significant difference between species and metals ( $p$-value $<0.05)$. All samples were considered for the statistical analysis and when the sample reading was below the LOQ values, half of LOD values were considered as a sample reading.

\section{Health risk assessment}

The health risk assessment based on the legumes and cereals were conducted according to the Integrated Risk Information System (IRIS) of the US Environmental Protection Agency (US EPA) guidance (IRIS, 2018).

Provisional Tolerable Weekly Intake (PTWI) of As and $\mathrm{Cd}$ through consumption of cereals and legumes was calculated using the following equation (Popovic et al., 2018).

$$
\mathrm{PTWI}=\frac{C \times W C}{B W}
$$

$\mathrm{C}=$ concentration of metals in legumes and cereals $(\mathrm{mg} / \mathrm{kg})$.

$\mathrm{WC}=$ average per capita cereal and legume consumption per week (kg/week).

$\mathrm{BW}=$ average body weight $(\mathrm{kg})$.

The exposure rate of $\mathrm{Cd}$ and As through the legumes and cereals was calculated using the following equation (Hensawang and Chanpiwat, 2017)

$$
\text { Exposure rate }(\mathrm{ER})=\frac{C \times I R \times E D}{B W \times A T}
$$

$\mathrm{C}=$ concentration of metals in legumes and cereals $(\mathrm{mg} / \mathrm{kg})$.

$\mathrm{IR}=$ amount of legumes and cereal consumed ( $\mathrm{kg} /$ year).

$\mathrm{ED}=$ period of time in contact with the metal (year).

$\mathrm{BW}=$ average body weight $(\mathrm{kg})$.

$\mathrm{AT}=$ average time or period of exposure (day). 
Non-carcinogenic health risk was calculated based on the Hazard Quotient (HQ) value using the equation is below (Hensawang and Chanpiwat, 2017).

$$
\mathrm{HQ}=\frac{E R}{R f D}
$$

$\mathrm{RfD}=$ reference dose for $\mathrm{Cd}$ and As.

The carcinogenic risk was also calculated based on the following equation (Hensawang and Chanpiwat, 2017).

$$
\mathrm{AELCR}=\frac{\text { Exposure rate } \times S F}{D L \times 365}
$$

$\mathrm{AELCR}=$ annual excess lifetime cancer risk.

$\mathrm{SF}=$ cancer slope factor $(\mathrm{mg} / \mathrm{kg}$, day).

$\mathrm{DL}=$ average human longevity.

Due to non-availability of the per capita consumption data, we assume that our population consume World Health Organization (WHO) recommended amounts for pulses, nuts, and seeds groups, viz., $30 \mathrm{~g} /$ day at least as a part of the $400 \mathrm{~g}$ of fruit and vegetables (Nishida et al., 2004). The mean body weight of Sri Lankan male is $61.4 \mathrm{~kg}$ and the female is $54.6 \mathrm{~kg}$ (MHNIM, 2015). The average Sri Lankan life expectancy is 75 years (CBSL, 2017). The RfD values for As (inorganic) and $\mathrm{Cd}$ are $3 \times 10^{-4}$ and $1 \times 10^{-3} \mathrm{mg} / \mathrm{kg}$.day respectively and SF for As is $1.5 \mathrm{mg} / \mathrm{kg}$.day (Hensawang and Chanpiwat, 2017).

\section{Results and discussion}

\section{Method performance}

The microwave assisted digestion, atomic absorption spectroscopy method used in this study shows the higher accuracy of different types of legume and cereal matrices. The mean As and Cd concentration of the standard reference material $(n=10)$ was for Cd: $1.875 \mathrm{mg} / \mathrm{kg}$ (recovery $116 \%$ ) and for As: $0.056 \mathrm{mg} / \mathrm{kg}$ (recovery 114\%). The LOQ value for $\mathrm{Cd}$ and As were $0.006 \mathrm{mg} / \mathrm{kg}$ and $18.17 \mu \mathrm{g} / \mathrm{kg}$ respectively.

\section{Cadmium level in legumes and cereals}

The concentration $(\mu \mathrm{g} / \mathrm{kg}$, wet weight basis) of $\mathrm{Cd}$ in the foods studied are presented in Table 1 as mean, median and range. There was no significant difference in $\mathrm{Cd}$ levels between legumes and cereals $(p<0.05)$. The highest mean $(37.52 \mu \mathrm{g} / \mathrm{kg})$ and median $(27.68 \mu \mathrm{g} / \mathrm{kg}) \mathrm{Cd}$ level was in sesame (cereal) while the highest range was observed in maize (cereal), <LOQ- $122.2 \mu \mathrm{g} / \mathrm{kg}$. Apart from cowpea/black-eyed pea, all the samples had $\mathrm{Cd}$ levels of more than $10 \mu \mathrm{g} / \mathrm{kg}$. Cd levels have been reported in maize at $<0.01 \mathrm{mg} / \mathrm{kg}$ (dry weight) in Nigeria (Akinyele and Shokunbi, 2015), $0.07 \mathrm{mg} / \mathrm{kg}$ (dry weight) also in also Nigeria (Onianwa et al., 2000) and $0.007 \mathrm{mg} / \mathrm{kg}$ (dry weight) in Canada (Dabeka and McKenzie, 1995). Cadmium concentration in the sample of Spanish legume (lentils, bean, chickpea, and green peas) was not detected $0.018 \mathrm{mg} / \mathrm{kg}$ (Cabrera et al., 2003). This shows that the Cd concentrations obtained in this study are within the range reported in the literature. Commercially used phosphate fertilizers have a high levels of $\mathrm{Cd}$ and are extensively used in rice cultivation and are possible to add into the irrigation system (Diyabalanage et al., 2016), and this may be the reason for the record values of $\mathrm{Cd}$ in legumes and cereals from the North Central Province.

\section{Arsenic level in legumes and cereals}

Generally As is detected in all foods. The level is higher in fish, shellfish, and seaweed than cereals and vegetables (Hernández and Navarro, 2013). The total As (tAs) in legumes and cereals detected in this study are presented in Table 1. The recorded mean tAs level in all varieties was below $0.1 \mathrm{mg} / \mathrm{kg}$, except in the case of sesame. Corguinha et al. (2015), reported 19, 47 and $65 \mu \mathrm{g} / \mathrm{kg}$ (dry weight) of tAs in wheat, corn, and soybean respectively. Total arsenic exposures in the United States in between 2006 and 2008 were estimated for 16 population subgroups and ranged from 0.14 to $0.45 \mu \mathrm{g} / \mathrm{kg} /$ day (Jara and Winter, 2014). Liu et al. (2009), found a mean tAs of $0.11 \pm 0.02,0.14 \pm 0.14$ and $0.16 \pm 0.046 \mathrm{mg} / \mathrm{kg}$

\begin{tabular}{|c|c|c|c|c|c|c|}
\hline \multirow[t]{2}{*}{ Species } & \multicolumn{3}{|c|}{$\mathrm{Cd}(\mu \mathrm{g} / \mathrm{kg})$} & \multicolumn{3}{|c|}{ As $(\mu \mathrm{g} / \mathrm{kg})$} \\
\hline & Mean & Median & Range & Mean & Median & Range \\
\hline Mustard & 13.67 & 7.220 & $<$ LOQ-42.52 & $<\mathrm{LOQ}$ & $<\mathrm{LOQ}$ & $<\mathrm{LOQ}-61.84$ \\
\hline Maize & 10.37 & 4.882 & $<$ LOQ-122.2 & 90.94 & $<\mathrm{LOQ}$ & $<\mathrm{LOQ}-475.7$ \\
\hline Finger millet & 22.38 & 11.11 & $<$ LOQ-120.5 & 52.67 & $<\mathrm{LOQ}$ & $<\mathrm{LOQ}-602.5$ \\
\hline Sesame & 37.52 & 27.68 & $<$ LOQ-121.5 & 105.2 & $<\mathrm{LOQ}$ & $<\mathrm{LOQ}-519.7$ \\
\hline Cowpea & 7.930 & 3.036 & $<\mathrm{LOQ}-34.61$ & 60.25 & $<\mathrm{LOQ}$ & $<\mathrm{LOQ}-502.5$ \\
\hline Urad dal & 21.21 & 14.16 & $<$ LOQ-39.34 & 47.95 & $<\mathrm{LOQ}$ & $<\mathrm{LOQ}-198.5$ \\
\hline Foxtail millet & 22.34 & 22.57 & $<$ LOQ-49.99 & 29.40 & $<\mathrm{LOQ}$ & $<\mathrm{LOQ}-127.1$ \\
\hline Long bean & 11.53 & 3.316 & $<\mathrm{LOQ}-44.17$ & $<\mathrm{LOQ}$ & $<\mathrm{LOQ}$ & $<\mathrm{LOQ}$ \\
\hline Green gram & 27.53 & 16.85 & $<$ LOQ-117.4 & 46.69 & $<\mathrm{LOQ}$ & $<\mathrm{LOQ}-348.0$ \\
\hline
\end{tabular}

Table 1 Concentrations ( $\mu \mathrm{g} / \mathrm{kg}$, wet weight) of As and $\mathrm{Cd}$ in legumes and cereals 
Table 2 PTWI of As and Cd considering the recommended legumes and cereal per capita consumption (30 g/day)

\begin{tabular}{lllll}
\hline Metal & PTWI (expressed as \% of PTWI or TWI) & Established PTWI & Established TWI \\
\cline { 2 - 4 } & Male & Female & 15 & - \\
\hline As & 1.1 & 1.3 & 7 & - \\
Cd (PTWI) & 0.9 & 1.1 & - & 2.5 \\
Cd (TWI) & 2.7 & 3.0 & \\
\hline
\end{tabular}

(dry weight) in wheat grown in three areas in China. Škrbić and Onjia (2007), evaluated the content of different microelements in wheat grain cultivated in 14 regions of Serbia and found a range from $<50-162$ (mean 82) $\mu \mathrm{g} / \mathrm{kg}$ (dry weight). These results were comparable to the present results in cereal and legume species grown in Sri Lanka.

\section{Health risk assessment in consumption of legumes and cereal}

There is no As threshold level proposed by the World Health Organization (WHO) Codex Alimentarius Commission or the European Union (EU) for cereal and legumes. In generally tAs is analysed for dietary estimation, although it is the inorganic As (iAs) that shows major toxicity signs (Hensawang and Chanpiwat, 2017). The EU regulation number 2015/1006 establishes that the iAs level for rice should not exceed $200 \mu \mathrm{g} / \mathrm{kg}$ (non-parboiled milled polished or white rice) and $250 \mu \mathrm{g} / \mathrm{kg}$ (parboiled rice and husked rice) (EU/EC, 2015). However, we were unable to perform As speciation analysis due to non-availability of the facilities and lack of funds.

The Joint Expert Committee on Food Additives (JECFA) proposed $400 \mu \mathrm{g} / \mathrm{kg}$ wet weight as a threshold level of $\mathrm{Cd}$ in rice while the European Food Safety Authority (EFSA) proposed $200 \mu \mathrm{g} / \mathrm{kg}$ for rice (Corguinha et al., 2015). Applying the $\mathrm{Cd}$ regulated limits for the legumes and cereals studied; no samples exceeded the JECFA level or even the EFSA level.

The study carried out a health risk assessment with the derived values by comparing with the available toxicological guidelines. JECFA established the PTWI values while EFSA established the TWI values. For As, the PTWI value is $15 \mu \mathrm{g} / \mathrm{kg}$.bw. For $\mathrm{Cd}$, the PTWI value is $7 \mu \mathrm{g} / \mathrm{kg}$.bw while the TWI is $2.5 \mu \mathrm{g} / \mathrm{kg}$.bw. Legumes and cereals do not significantly contribute to the PTWI or TWI value (Table 2). Legume and cereal consumption represent less than $1 \%$ of PTWI and less than $3 \%$ TWI for $\mathrm{Cd}$ while it is less than $1.3 \%$ of the PTWI for As.
The computed non-carcinogenic health risk of As and $\mathrm{Cd}$ indicates that there is a slight risk from eating legumes and cereals (Table 3). According to earlier studies, if the Total Hazard Quotient (THQ) $\geq 1$, there is a potential health risk and it is necessary to intervene and take protective action (Gladyshev et al., 2009). The THQ calculated as a sum of HQ for each element was 0.6238 for males and 0.7015 for females. The dominating metal that could make the greater contribution to a higher THQ was As. The carcinogenic health risk from As in cereals and legumes is well below $1 \times 10^{-6}$ (Table 3) which is considered as the lowest acceptable level of risk (Popovic et al., 2018).

It is important to emphasize that this value may be an erroneous estimation as it was calculated based on the WHO recommended per capita legume and cereal consumption. The real consumption value may be less than this. Also, we assumed that $100 \%$ of the ingested As and $\mathrm{Cd}$ were bioavailable and did not consider the potential reduction in amounts while preparing and cooking. However, in the worst-case scenario, this result could be appropriate and thus highlights the requirement of total diet study from the toxicological viewpoint.

\section{Conclusion}

This study examined the toxicological risk due to two non-essential trace elements (As and $\mathrm{Cd}$ ) in nine different commonly consumed legumes and cereals in Sri Lanka. The results showed no significant difference in As and Cd levels among the samples studied. Arsenic was the most abundant non-essential trace element and it was the major contributor to non-carcinogenic health risk. The calculated PTWI, ER, HQ and AELCR values are below the published international regulations. However, it is necessary to note the contribution of THQ value through consumption of legumes and cereals. Some assumptions of this study may overestimate the risk and hence a comprehensive Total Diet Study (TDS) based on the toxicological endpoint should be carried out.

Table $3 \mathrm{ER}, \mathrm{HQ}$ and AELCR values in As and Cd through consumption of legumes and cereals

\begin{tabular}{|c|c|c|c|c|c|c|}
\hline \multirow[t]{2}{*}{ Metal } & \multicolumn{2}{|l|}{ ER } & \multicolumn{2}{|l|}{$\mathrm{HQ}$} & \multicolumn{2}{|l|}{ AELCR } \\
\hline & Males & Females & Males & Females & Males & Females \\
\hline As & $1.67 \times 10^{-4}$ & $1.88 \times 10^{-4}$ & 0.558 & 0.627 & $9.16 \times 10^{-9}$ & $1.03 \times 10^{-8}$ \\
\hline $\mathrm{Cd}$ & $6.63 \times 10^{-5}$ & $7.46 \times 10^{-5}$ & 0.066 & 0.075 & - & - \\
\hline
\end{tabular}




\section{Abbreviations}

AAS: Atomic Absorption Spectrophotometer; ACL: Analytical Chemistry Laboratory; AELCR: Annual excess lifetime cancer risk; As: Arsenic; ATSDR: Agency for Toxic Substances and Disease Registry; Cd: Cadmium; CKDu: Chronic kidney disease of unknown etiology; CRM: Certified Reference Materials; EFSA: European Food Safety Authority; GTA: Graphite tube atomizer; iAs: Inorganic; IRIS: Integrated Risk Information System; IRMM: Institute for Reference Materials and Measurement; JECFA: Joint Expert Committee on Food Additives; LOD: Limit of detection; LOQ: Limit of quantification; NARA: National Aquatic Resources Research and Development Agency; NETEs: Non-essential trace elements; PTWI: Provisional Tolerable Weekly Intake; tAs: Total Arsenic; TDS: Total Diet Study; THQ: Total Hazard Quotient; US EPA: US Environmental Protection Agency; WHO: World Health Organization.

\section{Acknowledgements}

Financial assistance from the District Secretariat Office of Anuradhapura, Sri Lanka is acknowledged.

\section{Funding}

The work was financially supported by the District Secretariat Office of Anuradhapura, Sri Lanka.

\section{Availability of data and materials}

Please contact corresponding author for data requests.

\section{Authors' contributions}

All authors contributed to the analysis, writing and improvement of the manuscript. All authors read and approved the final manuscript.

\section{Competing interests}

The authors declare that they have no competing interests.

\section{Publisher's Note}

Springer Nature remains neutral with regard to jurisdictional claims in published maps and institutional affiliations.

\section{Author details}

'Department of Physical Sciences, Faculty of Applied Sciences, Rajarata University of Sri Lanka, Mihintale, Sri Lanka. ${ }^{2}$ Analytical Chemistry Laboratory (ACL), National Aquatic Resources Research and Development Agency (NARA), Colombo-15, Sri Lanka.

Received: 9 November 2018 Accepted: 6 February 2019

Published online: 14 February 2019

\section{References}

Akinyele IO, Shokunbi OS. Concentrations of $\mathrm{Mn}, \mathrm{Fe}, \mathrm{Cu}, \mathrm{Zn}, \mathrm{Cr}, \mathrm{cd}, \mathrm{Pb}, \mathrm{Ni}$ in selected Nigerian tubers, legumes and cereals and estimates of the adult daily intakes. Food Chem. 2015;173:702-8.

ATSDR. ATSDR's substance priority list. Agency for Toxic Substances and Disease Registry. 2017. https://www.atsdr.cdc.gov/SPL/. Accessed 20 Dec 2018.

Bandara JMRS, Wijewardena HVP, Liyanege J, Upul MA, Bandara JMUA. Chronic renal failure in Sri Lanka caused by elevated dietary cadmium: Trojan horse of the green revolution. Toxicol Lett. 2010;198:33-9.

Bandarage, A. 2013. Political economy of epidemic kidney disease in Sri Lanka. SAGE Open, 1, 1-13.

Cabrera C, Lloris F, Giménez R, Olalla M, López MC. Mineral content in legumes and nuts: contribution to the Spanish dietary intake. Sci Total Environ. 2003:308:1-14

CBSL. Economic and social statistics of Sri Lanka-2017. In: Central Bank of Sri Lanka; 2017.

Corguinha APB, Souza GA d, Gonçalves VC, Carvalho C d A, Lima WEA d, Martins FAD, Yamanaka CH, Francisco EAB, Guilherme LRG. Assessing arsenic, cadmium, and lead contents in major crops in Brazil for food safety purposes. Journal of Food Composition and Analysis. 2015;37:143-50.

Dabeka RW, McKenzie AD. Survey of lead, cadmium, fluoride, nickel, and cobalt in food composites and estimation of dietary intakes of these elements by Canadians in 1986-1988. J AOAC Int. 1995;78:897-909.

Diyabalanage S, Navarathna T, Abeysundara HT, Rajapakse S, Chandrajith R. Trace elements in native and improved paddy rice from different climatic regions of Sri Lanka: implications for public health. Springer Plus. 2016;5:1864.
EU/EC. Commission Regulation (EC), No 2015/1006 of amending Regulation (EC) No 1881/2006 as regards maximum levels of inorganic arsenic in foodstuffs. Off J Eur Union. 2015;L161:14-6.

Gladyshev MI, Sushchik NN, Anishchenko OV, Makhutova ON, Kalachova GS, Gribovskaya IV. Benefit-risk ratio of food fish intake as the source of essential fatty acids vs. heavy metals: a case study of Siberian grayling from the Yenisei river. Food Chem. 2009;115:545-50.

Gunatilake SK, Samaratunga SS, Rubasinghe RT. Chronic kidney disease (CKD) in Sri Lanka - current research evidence justification: a review. Sabaragamuwa University Journal. 2014;13:31-58.

Hensawang S, Chanpiwat P. Health impact assessment of arsenic and cadmium intake via rice consumption in Bangkok, Thailand. Environ Monit Assess. 2017:189:599.

Hernández MR, Navarro BI. Survey of total mercury and arsenic content in infant cereals marketed in Spain and estimated dietary intake. Food Control. 2013;30:423-32.

Huang Y, Hu Y, Liu Y. Heavy metal accumulation in iron plaque and growth of rice plants upon exposure to single and combined contamination by copper, cadmium and lead. Acta Ecol Sin. 2009;29:320-6.

IRIS. 2018. Integrated Risk Information System. https:/wwww.epa.gov/iris [online] Accessed 20 Oct 2018.

Jara EA, Winter CK. Dietary exposure to total and inorganic arsenic in the United States, 2006-2008. International Journal of Food Contamination. 2014;1:3.

Jayasumana C, Paranagama P, Fonseka S, Amarasinghe M, Gunatilake S, Siribaddana S. Presence of arsenic in Sri Lankan rice. International Journal of Food Contamination. 2015;2(1).

Liu W-X, Liu J-W, Wu M-Z, Li Y, Zhao Y, Li S-R. Accumulation and translocation of toxic heavy metals in Winter wheat (Triticum aestivum L.) growing in agricultural soil of Zhengzhou, China. Bull Environ Contam Toxicol. 2009:82:343-7.

MHNIM. non communicable diseases risk factor survey Sri Lanka 2015. Sri Lanka: Ministry of Health Nutrition and Indigeneous Medicine; 2015.

Nishida C, Uauy R, Kumanyika S, Shetty P. The joint WHO/FAO expert consultation on diet, nutrition and the prevention of chronic diseases: process, product and policy implications. Public Health Nutr. 2004;7:245-50.

Onianwa PC, Lawal JA, Ogunkeye AA, Orejimi BM. Cadmium and nickel composition of Nigerian foods. J Food Compos Anal. 2000;13:961-9.

Popovic AR, Djinovic-Stojanovic JM, Djordjevic DS, Relic DJ, Vranic DV, Milijasevic MP, Pezo LL. Levels of toxic elements in canned fish from the Serbian markets and their health risks assessment. J Food Compos Anal. 2018;67:70-6.

Škrbić B, Onjia A. Multivariate analyses of microelement contents in wheat cultivated in Serbia (2002). Food Control. 2007;18:338-45.

Zhao F-J, Stroud JL, Eagling T, Dunham SJ, McGrath SP, Shewry PR. Accumulation, distribution, and speciation of arsenic in wheat grain. Environmental Science \& Technology. 2010;44:5464-8.
Ready to submit your research? Choose BMC and benefit from:
- fast, convenient online submission
- thorough peer review by experienced researchers in your field
- rapid publication on acceptance
- support for research data, including large and complex data types
- gold Open Access which fosters wider collaboration and increased citations
- maximum visibility for your research: over $100 \mathrm{M}$ website views per year
At BMC, research is always in progress.
Learn more biomedcentral.com/submissions 